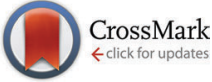

Cite this: Phys. Chem. Chem. Phys., 2016, 18, 8027

Received 21st November 2015, Accepted 16th February 2016

DOI: $10.1039 / \mathrm{c} 5 \mathrm{cp} 07171 \mathrm{~b}$

www.rsc.org/pccp

\section{Cage effects on conformational preference and photophysics in the host-guest complex of benzenediols with 18-Crown-6†}

\author{
Fumiya Morishima, Ryoji Kusaka, Yoshiya Inokuchi, Takeharu Haino and \\ Takayuki Ebata*
}

\begin{abstract}
The conformational preference and modification of photophysics of benzenediols, namely hydroquinone $(H Q)$, resorcinol (RE) and catechol (CA), upon host-guest complex formation with 18-Crown-6 (18C6) have been investigated, under supersonically jet-cooled conditions. Laser induced fluorescence (LIF) and UV-UV hole-burning spectra indicate the presence of two conformers for $\mathrm{HQ}$ and RE and one conformer for CA. On the other hand, the number of isomers is reduced to one in the 18C6.HQ and 18C6.RE complexes, while the 18C6.CA complex has three stable isomers. The IR spectra of the $\mathrm{OH}$ stretching vibration reveal that the two $\mathrm{OH}$ groups are H-bonded in 18C6.CA and 18C6.RE. In 18C6.RE, RE adopts the highest energy conformation in the bare form. In $18 \mathrm{C} 6 \cdot \mathrm{HQ}$, the $\mathrm{H}$-bonding of one $\mathrm{OH}$ group affects the orientation of the other $\mathrm{OH}$ group. The complex formation changes the photophysics of the $\mathrm{S}_{1}$ state of the benzenediols in a different manner. In our previous work, we reported a remarkable $S_{1}$ lifetime elongation in 18C6.CA complexes; the $S_{1}$ lifetime of CA is elongated more than 1000 times longer ( 8 ps $\rightarrow 10.3 \mathrm{~ns}$ ) in 18C6.CA (F. Morishima et al., J. Phys. Chem. B, 2015, 119, 2557-2565), which we called the "cage effect". In 18C6.RE, the increase of $S_{1}$ lifetime is moderate: 4.0 ns (monomer) $\rightarrow 10.5 \mathrm{~ns}$ (complex). On the other hand, the $\mathrm{S}_{1}$ lifetime of $\mathrm{HQ}$ is shortened in 18C6.HQ: $2.6 \mathrm{~ns}$ (monomer) $\rightarrow 0.54 \mathrm{~ns}$ (complex). Density functional theory (DFT) calculations suggest that these behaviors are related to the $S_{1}\left({ }^{1} \pi \pi^{\star}\right)-{ }^{1} \pi \sigma^{\star}$ energy gap, the character of the $\mathrm{S}_{2}$ state and the symmetry of benzenediol. These experimental results clearly show the potential ability of $18 \mathrm{C} 6$ to control the conformation and modification of the electronic structure of guest species.
\end{abstract}

\section{Introduction}

Crown ethers (CEs) have been widely known as functional molecules, especially as inclusion compounds in host-guest chemistry. CEs can hold cations in their cavity and are soluble in organic solvents as well as protic solvents. Owing to these characteristics, they are used as phase transfer catalysts. It is also known that CEs exhibit a preference to encapsulate cations in bulk, depending on the size matching between the cation and the CE cavity. Applications of CEs as molecular receptors, metal cation extraction agents, fluoroionophores and phase transfer catalytic media have been described in a number of studies. ${ }^{1-24}$ CEs can include not only metal ions but also various ionic and neutral species through non-covalent interactions. ${ }^{25-31}$ In our previous study, we investigated the structure of a cold $3 n$-Crown- $n \cdot$ phenol neutral complex $(n=5-8)^{29}$ and found that

Department of Chemistry, Graduate School of Science, Hiroshima University, Higashi-Hiroshima 739-8526, Japan. E-mail: tebata@hiroshima-u.ac.jp $\dagger$ Electronic supplementary information (ESI) available. See DOI: 10.1039/ c5cp07171b 18-crown-6 (18C6) and phenol form a single substantially stable 18C6.phenol 1:1 host-guest complex. 18C6 modifies its shape to be nicely matched to phenol showing "induced fit". The structure is strongly stabilized by collective intermolecular interactions, such as $\mathrm{OH} \cdots \mathrm{O} \mathrm{H}$-bonding and $\mathrm{CH} \cdots \pi$ bonding. Furthermore, we recently studied the 18C6.catechol (CA) host-guest complex and found that 18C6 modifies not only the geometrical but also the excited state electronic structures of the guest species, ${ }^{31}$ that is the $S_{1}$ lifetime of the CA monomer, $8 \mathrm{ps}$, becomes $10.3 \mathrm{~ns}$ in the 18C6.CA complex. This remarkable elongation of the $S_{1}$ lifetime was interpreted to be due to the destruction of the $\pi \sigma^{*}$ character of the $S_{2}$ state by 18C6, which is generally responsible for the nonradiative decay of the $S_{1}$ state. $^{31}$

In the present work, we extend our study to the host-guest complexes of all the benzenediols, hydroquinone (HQ), resorcinol (RE) and CA, with 18C6. We investigate their structures and the effect of complex formation on the $S_{1}$ dynamics of benzenediols. Particularly, CA has only one stable conformation, while HQ has two and RE has three possible conformations arising from the orientation of two $\mathrm{OH}$ groups. We first investigate how the 
conformations of benzenediols and 18C6 are modified for forming the stable host-guest complex through "induced-fitting". We then investigate how the complex formation changes the electronic structure of benzenediols by measuring their $\mathrm{S}_{1}$ lifetime. We apply various laser spectroscopic methods for the supersonically cooled molecules and complexes to measure the electronic and IR spectra. The number of conformers and isomers is determined by UV-UV hole-burning spectroscopy, and the structure of the specific isomer is investigated by IR-UV double resonance spectroscopy and quantum chemical calculations at density functional theory. The $S_{1}$ state lifetime is obtained by deconvoluting the fluorescence decay profiles or the picosecond pump-probe time profiles. We will discuss how the induced-fit model can be applied for forming the most stable complex structures and how the complex formation affects the excited state electronic structure of guest benzenediols.

\section{Experimental and computational}

\subsection{Experimental}

Details of the experimental setup have been described elsewhere. ${ }^{32}$ The supersonic free jet of benzenediol and 18C6.benzenediol complexes was generated by the supersonic expansion of a gaseous mixture of 18C6 and benzenediols diluted in He carrier gas (4 bar). The solid $18 \mathrm{C} 6$ and benzenediol samples were separately heated at different sample housings (340-370 K for 18C6, and 348, 363 and $473 \mathrm{~K}$ for $\mathrm{CA}, \mathrm{RE}$ and HQ respectively) to be vaporized. The gas mixture was expanded into a vacuum chamber through a $1 \mathrm{~mm}$ orifice of a pulsed nozzle. The $\mathrm{S}_{1}-\mathrm{S}_{0}$ electronic spectra were observed by laser induced fluorescence (LIF) spectroscopy. A tunable UV light obtained by frequency doubling the output of $\mathrm{Nd}^{3+}$ :YAG laser pumped dye laser (Lambda Physik Scanmate/Continuum Surelite II) was introduced into the vacuum chamber to be crossed with the supersonic jet at $\sim 30 \mathrm{~mm}$ downstream $(x / D=30)$ of the orifice. The LIF spectra were obtained by detecting the total fluorescence as a function of UV frequency. The vibronic bands belonging to different isomers were discriminated by UV-UV hole-burning (HB) spectroscopy; ${ }^{33}$ the frequency of the probe UV laser was fixed to a certain vibronic band of a specific species and its fluorescence intensity was monitored. Under these conditions, another tunable UV laser (hole burning (HB) laser) pulse obtained by SHG of the $\mathrm{Nd}^{3+}$ :YAG laser pumped dye laser (Continuum ND6000/Surelite II) was introduced at $10 \mathrm{~mm}$ upstream of the crossing point between the jet and the probe laser with a timing of $\sim 4 \mu$ s prior to the probe laser pulse. Then the depletion of the fluorescence intensity induced by the $\mathrm{HB}$ laser was monitored by scanning the frequency of the UV HB laser. The UV-UV HB spectra were thus obtained as dip spectra. For IR-UV double resonance (DR) spectroscopy, the output of a pulsed tunable OPO IR laser (LaserVision pumped by Quanta-Ray GCR250) was employed as a HB laser. The IR laser was introduced coaxially to the probe UV pulse with an interval of $80 \mathrm{~ns}$ prior to the UV pulse. The UV probe laser frequency was fixed to a certain vibronic band and the IR laser frequency was scanned. The depletion of the fluorescence induced by the IR pump laser was detected, giving fluorescence-dip IR spectra for the UV monitored species.

The $\mathrm{S}_{1}$ lifetimes of 18C6.CA and 18C6.RE complexes were obtained by deconvoluting the time profiles of the fluorescence decay curves by assuming the laser pulse shape as a Gaussian function with a $4.5 \mathrm{~ns}$ pulse width. The $\mathrm{S}_{1}$ lifetimes of benzenediol monomers and $\mathrm{H}_{2} \mathrm{O} \cdot \mathrm{HQ}$ and 18C6.HQ complexes were too short to be determined from the fluorescence decay, so that they were obtained by pump-probe experiments using a picosecond laser system. In this experiment, the molecules or complexes in the molecular beam were ionized by stepwise two-photon ionization with two picosecond lasers. The setup of the picosecond laser system has also been described in detail elsewhere. ${ }^{34,35}$ The first picosecond pump pulse excites the molecules or complexes to the $S_{1}$ origin, and the second probe laser pulse ionizes the $S_{1}$ state species. The ions are mass-analyzed with a $50 \mathrm{~cm}$ time-offlight tube and are detected using a channeltron (Burle 4900). The ion signals were processed by using a boxcar integrator (Par model 4401/4420) connected with a PC. By changing the delay time between the pump and probe lasers, the decay time profile of the $S_{1}$ state was obtained. The decay time constants were determined by deconvoluting the time profiles with the 12 ps laser pulses. All the decay curves were fitted as a single exponential decay. 18C6 and all benzenediols were purchased from Sigma-Aldrich and Nacalai Tesque, respectively, and used without further purification.

\subsection{Computational}

The initial structures of 18C6.benzenediol complexes were obtained by Monte Carlo simulation by mixed torsional search with low-mode sampling ${ }^{36}$ in MacroModel V.9.1 ${ }^{37}$ with the MMFF94s force field. ${ }^{38}$ The geometries were optimized by the PRCG algorithm with a convergence threshold of $0.05 \mathrm{~kJ} \mathrm{~mol}^{-1}$. From this calculation, 165 isomers for $18 \mathrm{C} 6 \cdot \mathrm{HQ}, 46$ isomers for 18C6.RE and 193 isomers for 18C6.CA were obtained, within $20 \mathrm{~kJ} \mathrm{~mol}^{-1}$ of the most stable one. All of these isomers were geometry-optimized by density functional theory (DFT) calculations at the $\mathrm{M} 05-2 \mathrm{X} / 6-31+\mathrm{G}^{*}$ level with loose optimization criteria. This calculation yielded 5, 19, and 61 isomers for 18C6.HQ, 18C6. RE and 18C6. CA, respectively, within $20 \mathrm{~kJ} \mathrm{~mol}^{-1}$. These loose-optimized isomers were further optimized at the $\omega \mathrm{B} 97 \mathrm{X}-\mathrm{D} / 6-31++\mathrm{G}^{* *}$ level with tight optimization criteria and ultrafine grid. The total energies were corrected by nonscaled zero-point vibrational energy (ZPE). The interaction energy $\left(E_{\text {int }}\right)$ of 18C6-benzenediol complexes was computed with counterpoise correction to remove the basis set superposition error (BSSE),

$$
\begin{aligned}
E_{\text {int }}(18 \mathrm{C} 6 \cdots \text { benzenediol })= & E(18 \mathrm{C} 6 \cdots \text { benzenediol }) \\
& -E(18 \mathrm{C} 6)-E_{\text {int }}(\text { benzenediol }) \\
& +E_{\mathrm{BSSE}}(18 \mathrm{C} 6 \cdots \text { benzenediol })
\end{aligned}
$$

where conformations of 18C6 and benzenediol fragments were the same as those in the 18C6.benzenediol complex. The IR spectra were obtained by vibrational analysis, and the vertical electronic transition energies were obtained by TD-DFT calculations 
at the $\omega \mathrm{B} 97 \mathrm{X}-\mathrm{D} / 6-31++\mathrm{G}^{* *}$ level. All the DFT calculations were performed using the Gaussian 09 package, revision D.01. ${ }^{39}$ The $\mathrm{OH}$ stretching frequencies were scaled by $0.9346,0.9325$ and 0.9325 for $\mathrm{HQ}, \mathrm{RE}$, and $\mathrm{CA}$, respectively, to reproduce the observed $\mathrm{OH}$ stretching vibration of each monomer. Though the calculated electronic energies are the vertical excitation energies, they are scaled by $0.8645,0.8603$ and 0.8598 , for HQ, RE and CA, respectively, to reproduce the observed $\mathrm{S}_{1}-\mathrm{S}_{0}$ band origin energy of each monomer.

\section{Results}

\section{1 $S_{1}-S_{0}$ spectra of benzenediols and their complexes}

Fig. 1 shows the LIF and UV-UV HB spectra of the $S_{1}-S_{0}$ transition of jet cooled $\mathrm{HQ}, \mathrm{RE}$, and $\mathrm{CA}$ and their complexes with 18C6. Fig. 1(a) shows the LIF spectrum of HQ in the $S_{1}-S_{0}$ band origin region. Two strong bands at 33515 and $33550 \mathrm{~cm}^{-1}$ are already assigned to the 0,0 band of two conformers of HQ, namely trans- and cis-HQ, respectively ${ }^{40}$ (see Scheme 1). Weak bands at 33164 and $33201 \mathrm{~cm}^{-1}$ are the band origins of the $\mathrm{H}_{2} \mathrm{O} \cdot \mathrm{HQ} 1: 1$ complex $^{41}$ due to the residual water in the sample. Fig. 1(b) shows the LIF spectrum measured by adding 18C6 vapor to the gas mixture. New bands appearing around 33100$33200 \mathrm{~cm}^{-1}$ can be assigned to the 18C6.HQ 1:1 complex. The UV-UV HB spectrum obtained by monitoring band $\mathrm{A}_{\mathrm{HQ}}$ is shown in Fig. 1(c). This result clearly shows that the 18C6.HQ 1:1 complex has a single isomer in spite of the fact that the HQ monomer has two conformers with almost equal abundance. The ratio of the band intensity for cis-HQ/trans-HQ is 0.86 without $18 \mathrm{C} 6$ vapor, while it becomes 0.57 with $18 \mathrm{C} 6$ vapor, indicating that the relative abundance of cis-HQ is reduced by the addition of 18C6 and that the cis-HQ conformer prefers the complex formation with $18 \mathrm{C} 6$ more than trans-HQ.

Fig. 1(d) and (e) exhibit the LIF spectra of RE without and with $18 \mathrm{C} 6$ vapor, respectively. The RE monomer has three
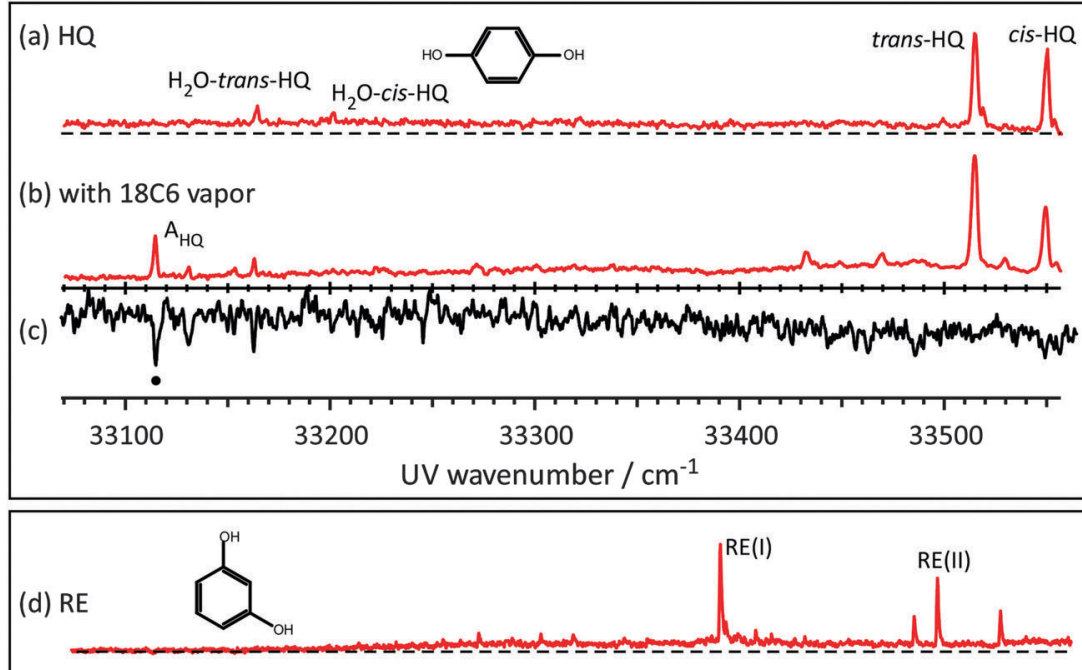

(e) with $18 \mathrm{C} 6$ vapor
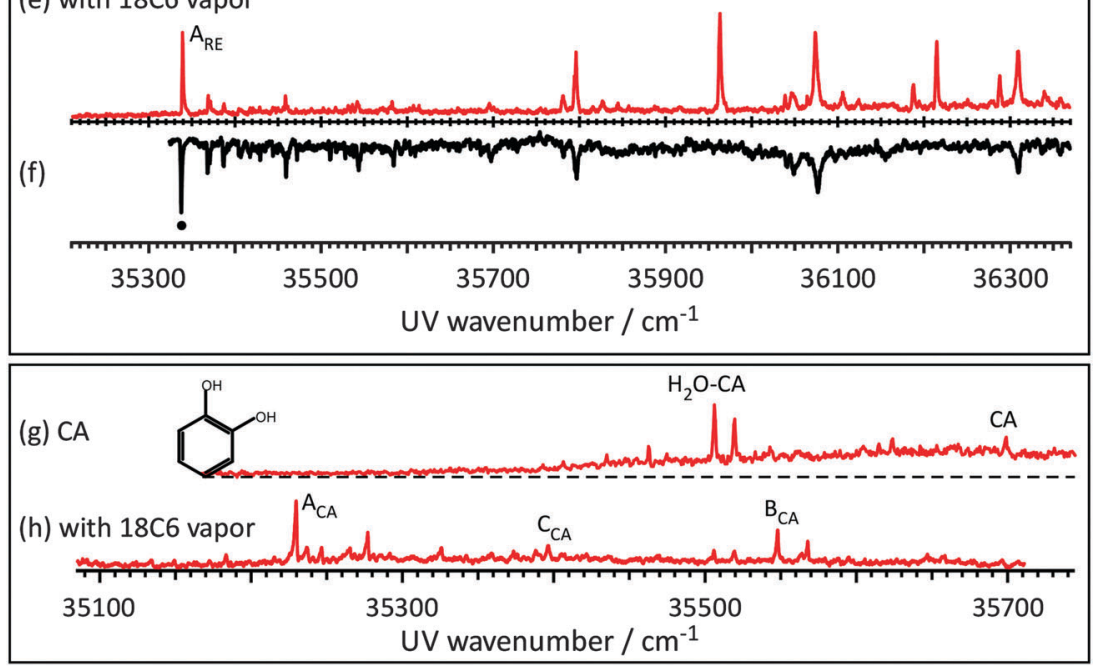

Fig. 1 The $\mathrm{S}_{1}-\mathrm{S}_{0}$ LIF spectra of jet-cooled (a) HQ, (b) 18C6.HQ complex, (d) RE, (e) 18C6.RE complex, (g) CA and (h) 18C6.CA complex in the band origin region. (c) and (f) The UV-UV hole-burning spectra of $18 \mathrm{C} 6 \cdot \mathrm{HQ}$ and18C6.RE, respectively. 
<smiles>O=COc1ccc(OC=O)cc1</smiles>

Resorcinol(RE)<smiles>Oc1cccc(O)c1</smiles><smiles>Oc1cccc(O)c1</smiles>

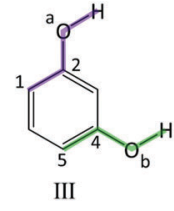

Scheme 1

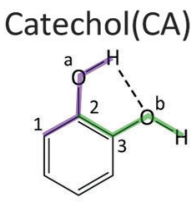

18-Crown-6(18C6)

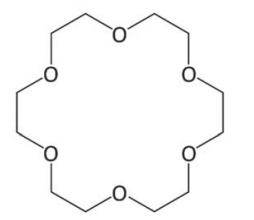

possible conformations (see Scheme 1, conformers I, II and III). Hereafter we call these conformers RE(I), RE(II) and RE(III), respectively. The bands at 35965 and $36217 \mathrm{~cm}^{-1}$ are assigned to the 0,0 band of $\operatorname{RE}(\mathrm{I})$ and $\operatorname{RE}(\mathrm{II})$, respectively. ${ }^{42}$ Thus, under the present jet-cooled conditions, only $\mathrm{RE}(\mathrm{I})$ and $\mathrm{RE}(\mathrm{II})$ are observed in the LIF spectrum. The total energy of RE(III) is $8.86 \mathrm{~kJ} \mathrm{~mol}^{-1}$ higher than that of $\mathrm{RE}(\mathrm{I})$ at the present level of the calculation, and the electronic transition of RE(III) appears only under warmer jet conditions. ${ }^{43}$ By the addition of $18 \mathrm{C} 6$ vapor, many bands due to the 18C6.RE $1: 1$ complex appear as seen in Fig. 1(e). The UV-UV HB spectrum in Fig. 1(f) indicates that they belong to the same isomer showing the band $\mathrm{A}_{\mathrm{RE}}$ $\left(35339 \mathrm{~cm}^{-1}\right)$ as the 0,0 band. Thus, the 18C6.RE $1: 1$ complex has only one isomer although the RE monomer has three possible conformations.

Fig. 1(g) and 1(h) show the LIF spectra of CA without and with 18C6 vapor, respectively. The spectra are essentially the same as those reported in our previous paper. ${ }^{31}$ The band labeled CA in Fig. $1(\mathrm{~g})$ at $35695 \mathrm{~cm}^{-1}$ is the 0,0 band of the CA monomer. In the spectrum, the bands of the $\mathrm{H}_{2} \mathrm{O} \cdot \mathrm{CA}$ complex also appeared. This is due to the presence of residual water in the sample. In $\mathrm{CA}$, two adjacent $\mathrm{OH}$ groups form an intramolecular $\mathrm{H}$-bond, so that it has a stable single conformer as seen in Scheme 1. The intensity of band CA in Fig. $1(\mathrm{~g})$ is very weak due to the fast internal conversion (IC) to the ${ }^{1} \pi \sigma^{*}$ state. On the other hand, the band intensities of the 18C6.CA 1:1 complex in Fig. 1(h) are much stronger. The UV-UV HB spectra, not shown here, indicate that the new bands in Fig. 1(h) are attributed to vibronic bands belonging to either of three species labeled $\mathrm{A}_{\mathrm{CA}}-\mathrm{C}_{\mathrm{CA}} \cdot{ }^{31}$ Thus, the 18C6.CA complex has three stable isomers, although bare CA has only one conformation. This is in contrast to the other two benzenediols, HQ and RE. The structures of the 18C6.benzenediol 1:1 complexes will be described in a later section. The frequencies of the 0,0 bands of the $S_{1}-S_{0}$ transition for the observed species are listed in Table 1.

\subsection{IR spectra of benzenediols and $18 \mathrm{C6} \cdot$ benzenediol complexes in the $S_{0}$ state}

Fig. 2(a)-(i) display the IR-UV DR spectra of HQ, RE, CA and their complexes with $18 \mathrm{C} 6$ in the $\mathrm{OH}$ stretching frequency region obtained by monitoring their 0,0 bands. For the CA monomer, the position of the IR bands reported in a previous

Table 1 Observed and calculated frequencies of the $\mathrm{OH}$ stretching vibrations, observed $\mathrm{S}_{1}-\mathrm{S}_{0}$ transition energy, calculated vertical $\mathrm{S}_{1}-\mathrm{S}_{0}$ and $\mathrm{S}_{2}-\mathrm{S}_{0}$ transition energies and oscillator strengths, $S_{2}-S_{1}$ energy gap $\left(\Delta E_{2-1}\right)$, observed $S_{1}$ lifetime and molecular symmetry of each species. The calculations are performed at the $\omega \mathrm{B} 97 \mathrm{X}-\mathrm{D} / 6-31++\mathrm{G}^{* *}$ level

\begin{tabular}{|c|c|c|c|c|c|c|c|c|c|c|}
\hline & \multirow[b]{2}{*}{$\begin{array}{l}\text { Band } \\
\text { labeling }\end{array}$} & \multicolumn{2}{|c|}{ OH stretching freq. $\left[\mathrm{cm}^{-1}\right]$} & \multirow[b]{2}{*}{$\begin{array}{l}\mathrm{S}_{1}-\mathrm{S}_{0} \text { transition } \\
\text { energy }\left[\mathrm{cm}^{-1}(\mathrm{eV})\right]\end{array}$} & \multicolumn{2}{|c|}{$\begin{array}{l}\text { Excitation energy }[\mathrm{eV}] \\
\text { and oscillator strength }^{a} \\
\end{array}$} & \multirow[b]{2}{*}{$\begin{array}{l}\Delta E_{2-1} \\
{[\mathrm{eV}]}\end{array}$} & \multirow[b]{2}{*}{$\begin{array}{l}\mathrm{S}_{1} \text { lifetime } \\
{[\mathrm{ns}]}\end{array}$} & \multirow[b]{2}{*}{$\begin{array}{l}\text { Symmetry } \\
\text { in } \mathrm{S}_{0}\end{array}$} & \multirow[b]{2}{*}{$\begin{array}{l}\text { Symmetry } \\
\text { in } \mathrm{S}_{1}{ }^{b}\end{array}$} \\
\hline & & Obs. & Calc. & & $\mathrm{S}_{1}$ & $\mathrm{~S}_{2}$ & & & & \\
\hline cis-HQ & - & 3663 & 3662,3663 & $33550(4.160)$ & $4.161(0.0706)$ & $4.649(0.0000)$ & 0.488 & 2.6 & $C_{2 \mathrm{~h}}$ & $C_{2 \mathrm{~h}}$ \\
\hline trans-HQ & - & 3662 & 3663 & $33515(4.156)$ & $4.155(0.0715)$ & $4.726(0.0000)$ & 0.571 & & $C_{2 \mathrm{v}}$ & $C_{2 \mathrm{v}}$ \\
\hline $\mathrm{H}_{2} \mathrm{O} \cdot c i s-\mathrm{HQ}$ & - & - & - & 33201 (4.117) & $4.112(0.0726)$ & $4.455(0.0000)$ & 0.343 & 1.2 & $C_{\mathrm{s}}$ & - \\
\hline $\mathrm{H}_{2} \mathrm{O} \cdot$ trans $-\mathrm{HQ}$ & - & - & - & 33164 (4.106) & $4.108(0.0727)$ & $4.510(0.0000)$ & 0.402 & & & \\
\hline 18C6.cis-HQ-I & $\mathrm{A}_{\mathrm{HQ}}$ & 3444,3657 & 3420,3653 & $33115(4.106)$ & $4.092(0.0740)$ & $4.588(0.0005)$ & 0.496 & 0.54 & $C_{1}$ & - \\
\hline 18C6.cis-HQ-II & - & - & 3410,3628 & - & $4.104(0.0729)$ & $4.758(0.0045)$ & 0.654 & - & & \\
\hline $\mathrm{RE}(\mathrm{I})$ & - & 3658 & 3656,3658 & $35965(4.460)$ & $4.465(0.0363)$ & $4.936(0.0007)$ & 0.471 & 4 & $C_{\mathrm{s}}$ & $C_{\mathrm{s}}$ \\
\hline RE(II) & - & 3658 & 3659 & 36217 (4.491) & $4.484(0.0257)$ & $4.923(0.0000)$ & 0.439 & & $C_{2 \mathrm{~h}}$ & $C_{2 \mathrm{~h}}$ \\
\hline RE(III) & - & - & - & - & $4.425(0.0482)$ & $4.894(0.0000)$ & 0.469 & - & $C_{2 \mathrm{~h}}$ & - \\
\hline 18C6·RE(III)-I & $A_{R E}$ & 3465 & 3371,3396 & 35339 (4.382) & $4.368(0.0316)$ & $4.880(0.0008)$ & 0.512 & 10.5 & $C_{1}$ & - \\
\hline 18C6·RE(III)-II & - & - & 3359,3401 & - & $4.343(0.0381)$ & $4.968(0.0008)$ & 0.625 & - & & \\
\hline 18C6·RE(III)-III & - & - & 3391,3429 & - & $4.371(0.0365)$ & $4.843(0.0000)$ & 0.472 & - & & \\
\hline 18C6·RE(III)-IV & - & - & 3358,3369 & - & $4.359(0.0417)$ & $4.838(0.0000)$ & 0.479 & - & & \\
\hline 18C6·RE(III)-V & - & - & 3412,3462 & - & $4.398(0.0376)$ & $4.939(0.0001)$ & 0.541 & - & & \\
\hline CA & - & 3611,3673 & 3612,3672 & $35695(4.426)$ & $4.426(0.0507)$ & $4.682(0.0004)$ & 0.256 & 0.008 & $C_{\mathrm{s}}$ & $C_{1}$ \\
\hline 18C6.CA-A1 & $\mathrm{C}_{\mathrm{CA}}$ & 3281,3507 & 3311,3584 & $35397(4.389)$ & $4.347(0.0422)$ & $4.895(0.0020)$ & 0.548 & & & \\
\hline 18C6.CA-E1 & $\mathrm{A}_{\mathrm{CA}}$ & 3385,3407 & 3372,3429 & 35230 (4.369) & $4.320(0.0513)$ & $5.041(0.0241)$ & 0.721 & 10.3 & $C_{1}$ & - \\
\hline 18C6·CA-E4 & $\mathrm{B}_{\mathrm{CA}}$ & 3424 & 3386,3396 & $35548(4.408)$ & $4.354(0.0554)$ & $4.993(0.0181)$ & 0.639 & 10.3 & & \\
\hline
\end{tabular}

${ }^{a}$ Calculated energies are scaled by $0.8645,0.8603$ and 0.8598 for HQ, RE and CA, respectively, so as to reproduce the observed $\mathrm{S}_{1}-\mathrm{S}_{0}$ transition of each benzenediol monomer. ${ }^{b}$ Ref. 53 . 
study is shown as arrows. ${ }^{44}$ Table 1 also lists the observed frequencies of the $\mathrm{OH}$ stretching vibrations. The $\mathrm{OH}$ bands of trans- and cis-HQ appear at 3662 and $3663 \mathrm{~cm}^{-1}$, respectively. ${ }^{45}$ In $\mathrm{HQ}$, the two $\mathrm{OH}$ groups are symmetrically equivalent in the two conformers. So, the observed IR band is assigned to the antisymmetric $\mathrm{OH}$ stretching vibration in trans-HQ, while the symmetric and antisymmetric $\mathrm{OH}$ stretching vibrations are thought to be overlapped in cis-HQ. The IR spectrum of the 18C6.HQ complex $\left(\mathrm{A}_{\mathrm{HQ}}\right)$ is shown in Fig. 2(c). The bands at 3444 and $3657 \mathrm{~cm}^{-1}$ are assigned to the $\mathrm{H}$-bonded $\mathrm{OH}$ stretch and the free $\mathrm{OH}$ stretch, respectively. Several bands appearing at the higher frequency side of the $\mathrm{H}$-bonded $\mathrm{OH}$ are assigned to the combination bands with low frequency vibrations, probably intermolecular vibrations. Thus, in the 18C6.HQ complex, one $\mathrm{OH}$ group is $\mathrm{H}$-bonded and the other is free from the H-bond.

Fig. 2(d) and (e) show the IR spectra of the RE(I) and RE(II) monomers, respectively. In $\mathrm{RE}(\mathrm{II})$, the antisymmetric $\mathrm{OH}$ stretch band has a stronger IR intensity, while in RE(I) two $\mathrm{OH}$ bands may have similar intensity because of the lower molecular symmetry. Actually, in both RE(I) and RE(II), only

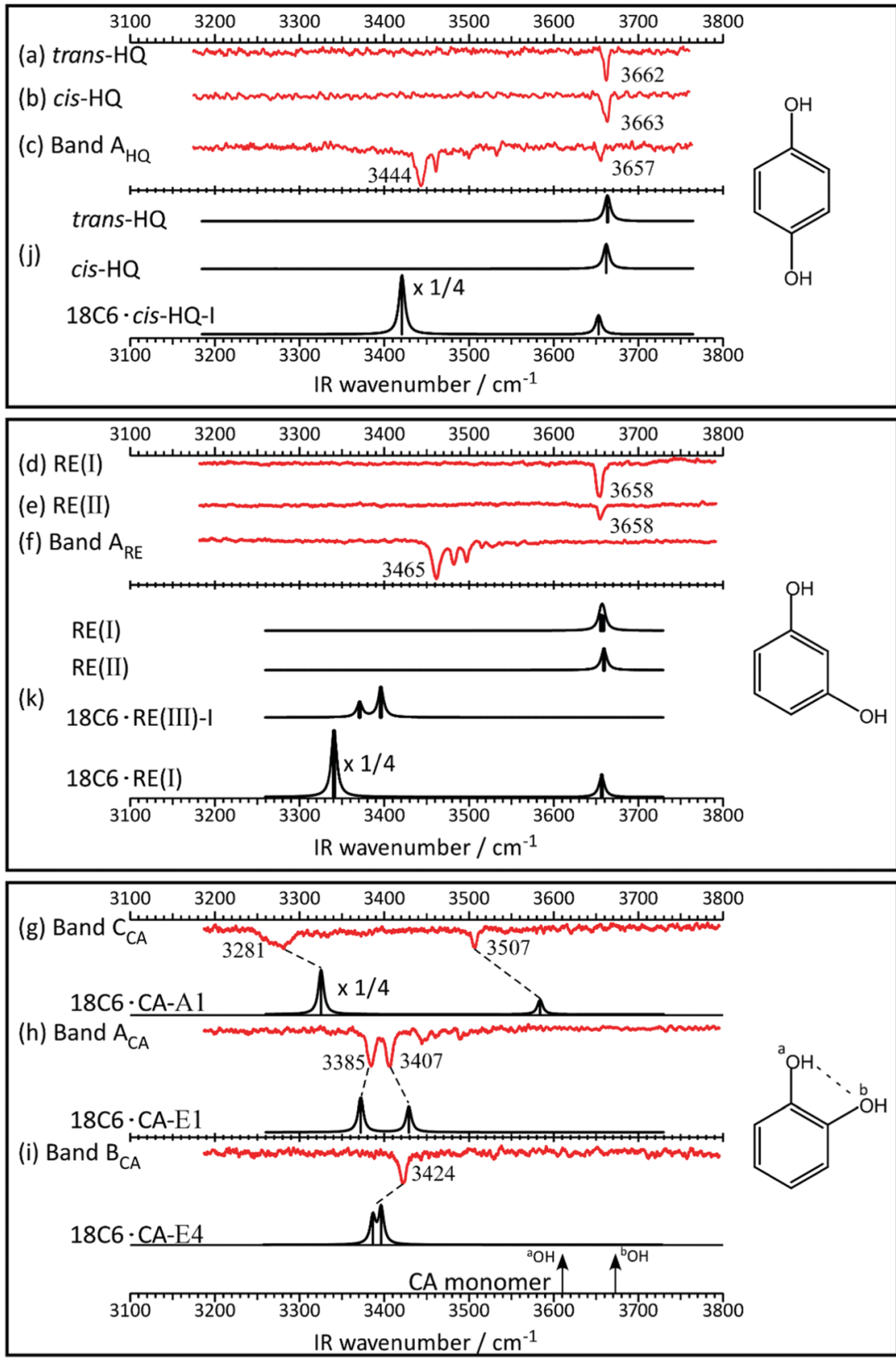

Fig. 2 (a)-(i) The IR-UV DR spectra of benzenediol monomers and their complexes with 18C6. (j) and ( $\mathrm{k}$ ) The calculated IR spectra of HQ and RE and the complexes with $18 C 6$ at the level of $\omega B 97 X-D / 6-31++G^{* *}$. In the IR spectra of 18C6.CA complexes, the calculated spectra are shown for comparison. Arrows represent the positions of the $\mathrm{OH}$ stretching vibrations of the $\mathrm{CA}$ monomer. The calculated IR frequencies are scaled by 0.9346 for $\mathrm{CA}$ and its complex, 0.9325 for RE and its complex, and 0.9325 for CA and its complex, in order to reproduce the observed OH stretching vibration of each monomer. 
one $\mathrm{OH}$ band appeared at the same frequency at $3658 \mathrm{~cm}^{-1}$ in the observed spectra. ${ }^{45}$ This result indicates that the coupling between the two $\mathrm{OH}$ groups is very weak, which is also supported in the calculated spectra of Fig. 2(k). In the IR-UV spectrum of the 18C6.RE complex ( $\mathrm{A}_{\mathrm{RE}}$ ) (Fig. 2(f)), no free $\mathrm{OH}$ band is seen at $\sim 3650 \mathrm{~cm}^{-1}$ and three bands appear in the $3460-3500 \mathrm{~cm}^{-1}$ region, which are assigned to the H-bonded $\mathrm{OH}$. Among them, the intensity of the lowest frequency band at $3465 \mathrm{~cm}^{-1}$ is the strongest. Since RE has only two $\mathrm{OH}$ groups, the appearance of three bands means that one of the two higher frequency bands is the combination band with a low frequency intermolecular vibration.

Fig. 2(g)-(i) display the IR-UV spectra (red curves) of 18C6.CA by monitoring the intensity of bands $\mathrm{C}_{\mathrm{CA}}, \mathrm{A}_{\mathrm{CA}}$ and $\mathrm{B}_{\mathrm{CA}}$, and the calculated IR spectra (black curves) of the corresponding structures. Since the IR spectrum of monomer CA could not be obtained because of its weak fluorescence intensity, we adopted the reported values of the frequencies of IR bands. ${ }^{44}$ The IR spectrum of species $\mathrm{C}_{\mathrm{CA}}$ shows a broad $\mathrm{OH}$ band centered at $3281 \mathrm{~cm}^{-1}$ and a sharp one at $3507 \mathrm{~cm}^{-1}$. The former band is assigned to the $\mathrm{H}$-bonded $\mathrm{OH}$ with $18 \mathrm{C} 6$ and the latter to the intramolecular $\mathrm{H}$-bonded $\mathrm{OH}$ band. The IR spectra of species $\mathrm{A}_{\mathrm{CA}}$ and $\mathrm{B}_{\mathrm{CA}}$ exhibit the $\mathrm{OH}$ bands at the $3350-3450 \mathrm{~cm}^{-1}$ region, indicating that the two $\mathrm{OH}$ groups are $\mathrm{H}$-bonded with $18 \mathrm{C} 6$ with almost equal strength. The assignments of the $\mathrm{OH}$ vibrations by comparison with the calculated ones will be given in a later section.

\section{3 $\mathrm{S}_{1}$ lifetimes of the benzenediol monomers and their complexes}

We then measured the $\mathrm{S}_{1}$ lifetime of each monomer and complexes. Fig. 3 shows the picosecond pump-probe decay profiles of (a) cis-HQ, (d) RE(I), (e) RE(II) and (g) CA monomers, respectively. They are observed by exciting at the 0,0 band of $S_{1}$, giving the lifetime of $2.6 \pm 0.2 \mathrm{~ns}, 4.2 \pm 0.3 \mathrm{~ns}, 4.5 \pm 0.5 \mathrm{~ns}$, and $8.0 \mathrm{ps}$, respectively. The very short $\mathrm{S}_{1}$ lifetime of CA was investigated by Livingstone et al. $^{46}$ and Chatterley et al. ${ }^{47}$ and is attributed to the fast IC to the nearby ${ }^{1} \pi \sigma^{*}$ state, leading to an atomic hydrogen elimination of the acceptor $\mathrm{OH}\left({ }^{b} \mathrm{OH}\right.$ in Scheme 1). Fig. 3(c), (f), (h) and (i) display the decay profiles of the 18C6 complexes. The change of the $\mathrm{S}_{1}$ lifetime upon complexation is quite different for different benzenediols; in the case of $\mathrm{HQ}$, the $\mathrm{S}_{1}$ lifetime of the 18C6.HQ complex ( $0.54 \mathrm{~ns}$, Fig. 3(c)) is shorter by a factor of 5 than that of the monomer. In contrast, the lifetime of the 18C6.RE complex (10.5 ns) is 2.5 times longer than that of the RE monomer, and the lifetime of the 18C6.CA complex (10.3 ns) is 1280 times longer than that of the CA monomer.

\section{Discussion}

\subsection{Structure of 18C6 benzenediol $1: 1$ complexes}

4.1.1 18C6.HQ complex. As shown in Fig. 1(c), only one isomer appears for the 18C6.HQ complex. The fact that the
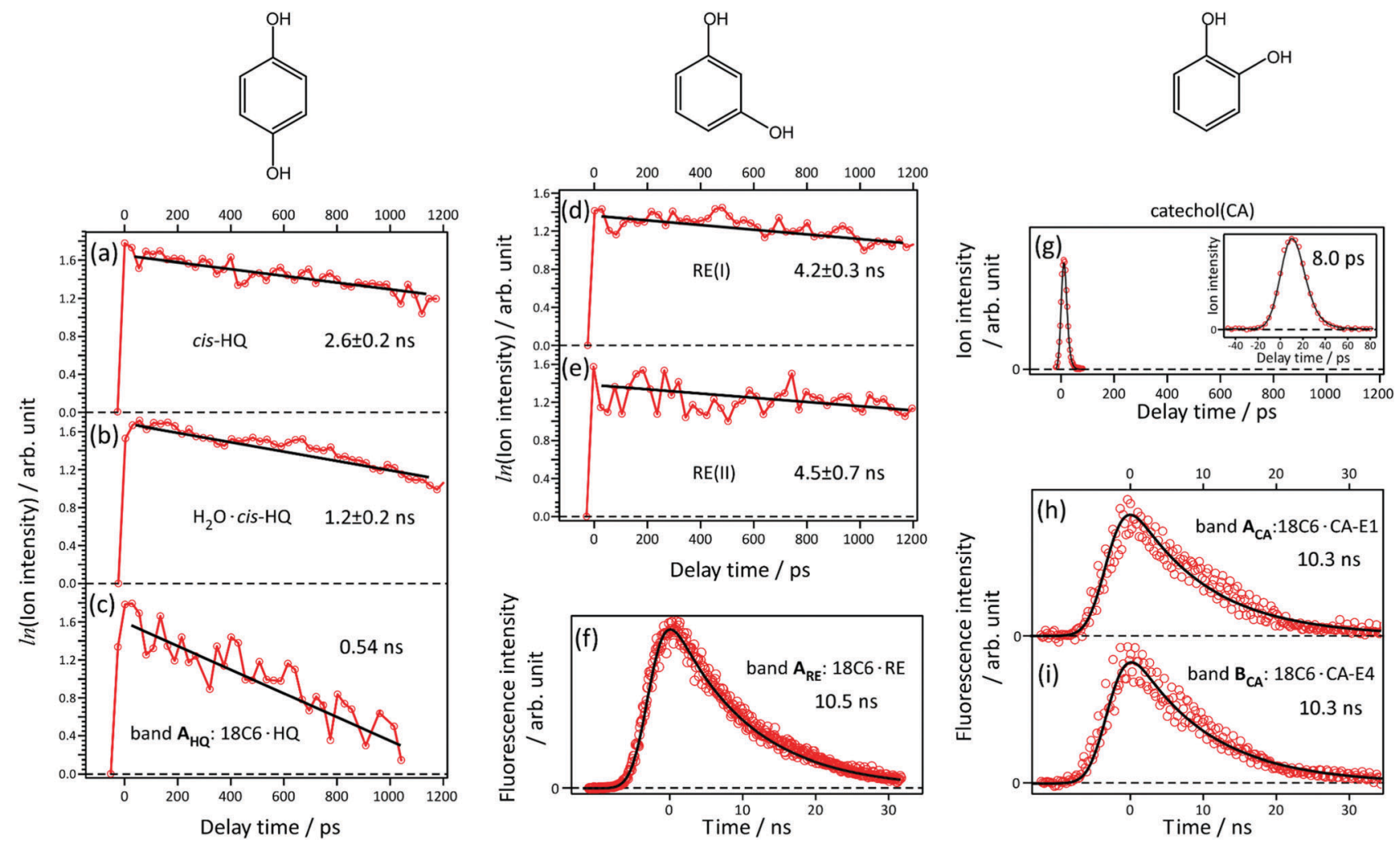

Fig. 3 Picosecond pump-probe decay profiles of (a)-(c) HQ monomers and the 18C6.HQ complex, (d and e) RE monomers and (g) CA monomer. Fluorescence decay curves of (f) the 18C6.RE complex and (h) and (i) 18C6.CA complexes, obtained using nanosecond laser excitation. The inset of (g) is the expanded view of the time profile of CA. 


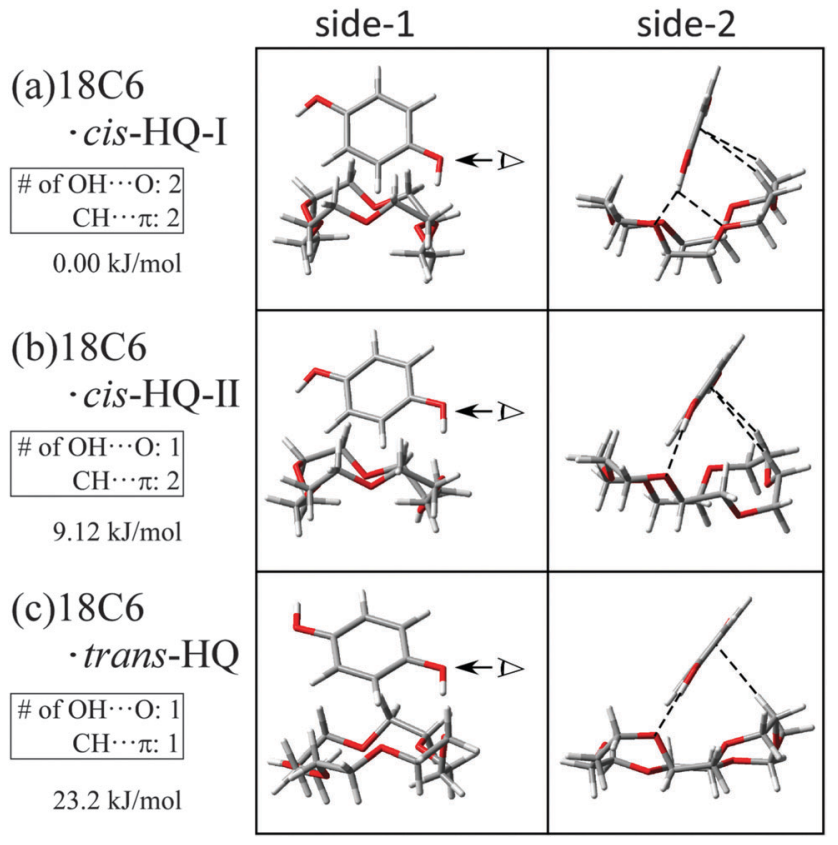

Fig. 4 (a) and (b) Structures of the lowest energy isomers of $18 \mathrm{C} 6 \cdot \mathrm{cis}-\mathrm{HQ}$ within the energy of $10 \mathrm{~kJ} \mathrm{~mol}{ }^{-1}$ at the level of $\omega \mathrm{B} 97 \mathrm{X}-\mathrm{D} / 6-31++\mathrm{G}^{\star *}$ calculation. (c) Structure of the 18C6.trans-HQ complex, which is $\sim 23 \mathrm{~kJ} \mathrm{~mol}^{-1}$ higher than 18C6.cis-HQ-I.

reduction of the band intensity of cis-HQ upon complex formation is greater than that of trans-HQ in the LIF spectrum suggests that the conformation of $\mathrm{HQ}$ in the 18C6.HQ complex can be the cis-form. Fig. 4(a) and (b) show the calculated most stable structures of the 18C6.HQ complex within the energy of $10 \mathrm{~kJ} \mathrm{~mol}^{-1}$. The relative energies of the isomers are also listed in Table 2. The dashed lines in Fig. 4 represent the $\mathrm{OH} \cdots \mathrm{O}$ $\left(r_{\mathrm{H} \cdots \mathrm{O}}<2.7 \AA\right)$ and $\mathrm{CH} \cdots \pi\left(r_{\mathrm{H} \cdots \pi}<3.0 \AA\right) \mathrm{H}$-bonding between HQ (guest) and 18C6 (host) molecules. In these structures, one $\mathrm{OH}$ group is $\mathrm{H}$-bonded to the oxygen atom in the ether ring and the opposite $\mathrm{OH}$ is free from an intermolecular $\mathrm{H}$-bond. These structures well describe the observed IR spectra of the $\mathrm{OH}$ stretching vibrations, that is one $\mathrm{OH}$ is $\mathrm{H}$-bonded and the other is free. An interesting point is that HQ adopts the cis-form in these conformers. This result is consistent with the experimental results that cis-HQ forms the complex more easily than trans-HQ. Of course, the trans-HQ may change to the cis-HQ upon complex formation. Anyway, the conformation preference of $\mathrm{HQ}$, cis-HQ, in 18C6.HQ becomes clear when we examine higher energy isomers. Fig. 4(c) shows the most stable 18C6.trans-HQ complex. This complex is $23.2 \mathrm{~kJ} \mathrm{~mol}^{-1}$ higher than the most stable 18C6.cis-HQ-I (Fig. 4(a)) so that the complex does not exist under jet-cooled conditions. The reason why HQ prefers the cis-form in the complex can be explained by the fact that the complex is largely stabilized by the dipole-dipole interaction between cis-HQ and 18C6; cis-HQ has a dipole moment of $2.789 \mathrm{D}$, while that of trans-HQ is almost zero. In addition, though the most stable $18 \mathrm{C} 6$ has a planar structure $\left(C_{\mathrm{i}}\right.$ symmetry) in the bare form, ${ }^{48-51}$ it changes the structure so that it has a dipole moment to include HQ. Thus, both the molecules cooperatively change the conformation to have dipole moments and stabilize during the process of the host-guest complex formation. Thus, the complex formation mechanism can be called as "induced-fitting".

Fig. 2(j) shows the calculated IR spectra of bare HQ and the 18C6.cis-HQ-I complex of Fig. 4(a). Both trans- and cis-HQ in the bare form show the free $\mathrm{OH}$ stretching bands at $3663 \mathrm{~cm}^{-1}$. In the complex, the calculated IR spectrum of 18C6.cis-HQ-I shows the $\mathrm{H}$-bonded $\left(3420 \mathrm{~cm}^{-1}\right)$ and free $\left(3653 \mathrm{~cm}^{-1}\right) \mathrm{OH}$ stretching vibrations, which nicely reproduces the observed spectrum of species $\mathrm{A}_{\mathrm{HQ}}$ (Fig. 2(c)). It should be noted that 18C6.cis-HQ-I, -II and 18C6.trans-HQ show very similar calculated IR spectra with each other (see Fig. S1, ESI†). Based on the relative energies and IR spectra, it is concluded that the structure of species $\mathrm{A}_{\mathrm{HQ}}$ is 18C6.cis-HQ-I. This complex is stabilized through multiple interactions such as the $\mathrm{OH} \cdots \mathrm{O} \mathrm{H}$-bond, $\mathrm{CH} \cdots \pi$, and dipoledipole interactions. This synergetic effect is very important for the stabilization and conformer preference of this host-guest complex.

4.1.2 18C6 RE complex. Fig. 5(a)-(e) show the stable isomers of the 18C6.RE complex within the energy of $10 \mathrm{~kJ} \mathrm{~mol}^{-1}$. As shown in Fig. 5, RE takes the RE(III) conformation in all isomers, which did not appear in the monomer form. Actually, the calculated energies of R(II) and R(III) are 0.40 and $8.86 \mathrm{~kJ} \mathrm{~mol}^{-1}$ higher than R(I) in the monomer. In the complex, however, the lowest energy isomer having $\mathrm{RE}(\mathrm{I})$ conformation (18C6. $\mathrm{RE}(\mathrm{I}))$ is $27.1 \mathrm{~kJ} \mathrm{~mol}^{-1}$ higher than $18 \mathrm{C} 6 \cdot \mathrm{RE}(\mathrm{III})-\mathrm{I}$ (see Fig. S2(a), ESI $\dagger$ ),

Table 2 Relative total energies $\left(\Delta E\left[\mathrm{~kJ} \mathrm{~mol}^{-1}\right]\right)$ of the complexes, interaction energies $\left(E_{\mathrm{int}}\left[\mathrm{kJ} \mathrm{mol}^{-1}\right]\right)$, relative energies of the conformers of the $18 \mathrm{C} 6$ $\operatorname{part}\left(\Delta E_{\mathrm{CE}}\left[\mathrm{kJ} \mathrm{mol}^{-1}\right]\right)$ and the benzenediol part $\left(\Delta E_{\mathrm{HQ}}\right.$, RE or CA $\left.\left[\mathrm{kJ} \mathrm{mol}^{-1}\right]\right)$ in the complexes, and dihedral angles of the OH groups of benzenediol in the complexes. The species with bold letters are those experimentally observed. The calculations are performed at the $\omega \mathrm{B} 97 \mathrm{X}-\mathrm{D} / 6-31++\mathrm{G} * *$ level

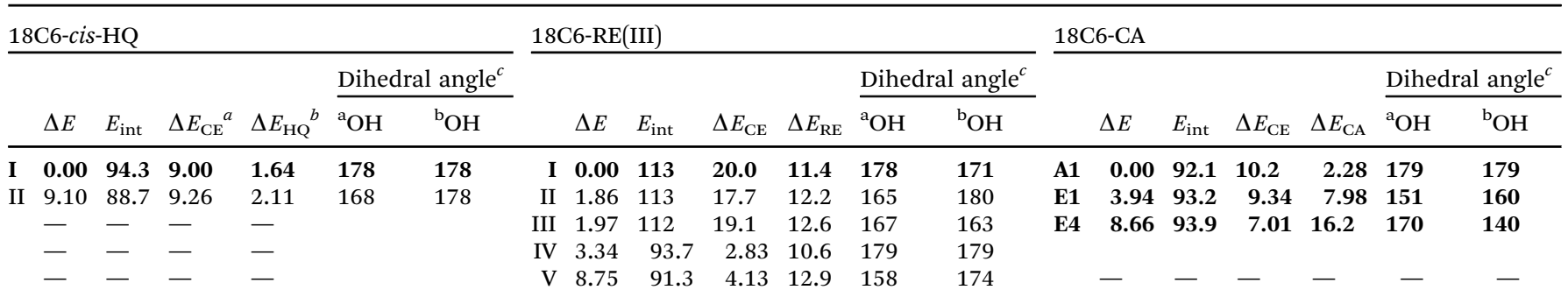

${ }^{a} \Delta E_{\mathrm{CE}}$ are relative values to that of the most stable $18 \mathrm{C} 6$ conformer in the monomer. ${ }^{b} \Delta E_{\mathrm{HQ}, \mathrm{RE} \text { or CA}}$ are relative values to that of the most stable conformer in each benzenediol monomer. ${ }^{c}$ Dihedral angles of ${ }^{\mathrm{a}} \mathrm{OH}$ and ${ }^{\mathrm{b}} \mathrm{OH}$ are defined in Scheme 1. 
side-1

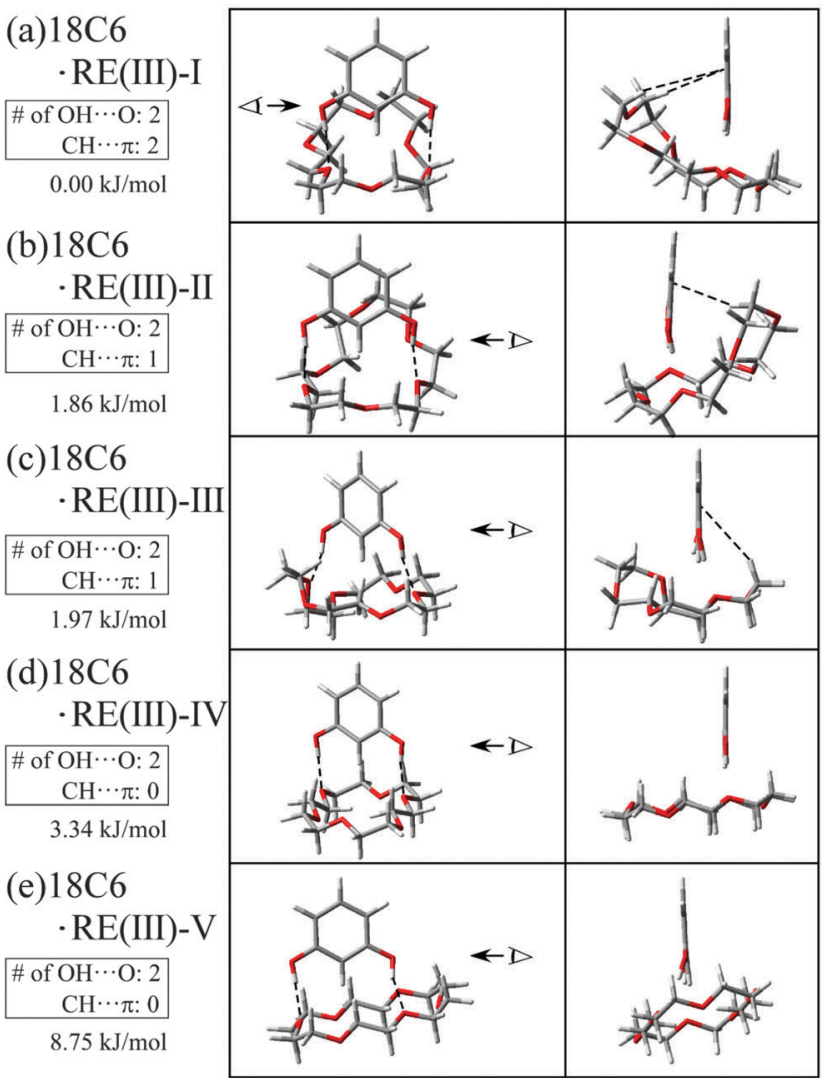

Fig. 5 (a)-(e) Structures of the lowest energy isomers of $18 C 6 \cdot R E(I I I)$ within the energy of $10 \mathrm{~kJ} \mathrm{~mol}^{-1}$ at the level of $\omega \mathrm{B} 97 \mathrm{X}-\mathrm{D} / 6-31++\mathrm{G}^{\star *}$ calculation.

and the 18C6.RE(II) isomer is not obtained as a stable structure even up to $40 \mathrm{~kJ} \mathrm{~mol}^{-1}$. The stability of the $18 \mathrm{C} 6 \cdot \mathrm{RE}(\mathrm{III})$ isomer mostly comes from the formation of two $\mathrm{OH} \cdots \mathrm{O}$ H-bonds as seen in Fig. 5. Fig. 2(k) shows the calculated IR spectra of RE(I), RE(II), 18C6.RE(III)-I and 18C6.RE(I). Similar to HQ, bare RE shows only a free $\mathrm{OH}$ stretch band. $\mathrm{RE}(\mathrm{I})$ and $\mathrm{RE}(\mathrm{II})$ have $C_{\mathrm{s}}$ and $C_{2 \mathrm{v}}$ symmetry, respectively. The two free $\mathrm{OH}$ bands are overlapped with each other with equal intensity in RE(I), but in RE(II) the anti-symmetric $\mathrm{OH}$ stretch band appears much stronger than the symmetric $\mathrm{OH}$ stretch. In any case, both the symmetric and anti-symmetric $\mathrm{OH}$ stretches have almost the same frequency. The IR spectrum of 18C6.RE(III)-I shows two H-bonded OH stretching vibrations at 3371 and $3396 \mathrm{~cm}^{-1}$, which reproduces the observed IR spectra of $A_{\mathrm{RE}}$. The IR spectrum of the 18C6.RE(I) isomer exhibits a free $\mathrm{OH}$ stretching vibration at $\sim 3655 \mathrm{~cm}^{-1}$, which does not reproduce the observed IR spectrum of $A_{R E}$. Thus, the observed species $A_{R E}$ is assigned to the 18C6-RE(III) isomer.

Similar to the case of HQ, multiple conformers coexist in the bare form in RE, but the complexation with 18C6 controls the conformation of RE to the highest energy one (RE(III)) to form the most stable complex. In addition, 18C6 also changes its conformation so as to fit the guest species in its cavity. The complex is finally stabilized by two $\mathrm{OH} \cdots \mathrm{O} \mathrm{H}$-bonds and $\mathrm{CH} \cdots \pi$ interactions, and this synergetic effect is also essential for the stabilization of the host-guest complex of crown ether.

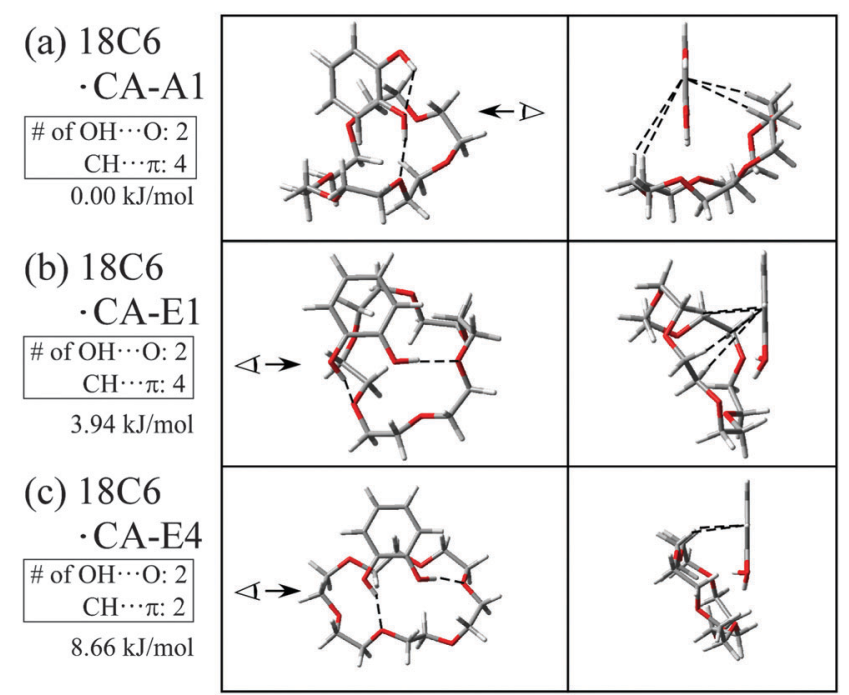

Fig. 6 (a) - (c) Structures of the observed three isomers of the $18 \mathrm{C} 6 \cdot \mathrm{CA}$ complexes determined at the level of $\omega \mathrm{B} 97 \mathrm{X}-\mathrm{D} / 6-31++\mathrm{G}^{* *}$ calculation.

4.1.3 18C6. CA complex. The difference between CA and the other benzenediols (HQ and $\mathrm{RE}$ ) is the presence of intramolecular $\mathrm{H}$-bonding in bare $\mathrm{CA}$, which leads to a unique feature of CA, such as the very short $\mathrm{S}_{1}$ lifetime compared to $\mathrm{HQ}$ or RE. Complexation with 18C6 largely affects this intramolecular H-bonding. Fig. 6 shows the calculated structures of 18C6. CA assignable to the observed three species, $\mathrm{A}_{\mathrm{CA}}, \mathrm{B}_{\mathrm{CA}}$ and $\mathrm{C}_{\mathrm{CA}}$, in our previous study. ${ }^{31}$ In that paper, species $\mathrm{A}_{\mathrm{CA}}$ and $\mathrm{B}_{\mathrm{CA}}$ were assigned to 18C6.CA-E1 (Fig. 6(b)) and 18C6.CA-E4 (Fig. 6(c)), respectively, in which the intramolecular $\mathrm{H}$-bonding of $\mathrm{CA}$ is broken and the two $\mathrm{OH}$ groups are independently H-bonded to the oxygen atoms of 18C6 (we call it Type-E). On the other hand, in species $\mathrm{C}_{\mathrm{CA}}$ (structure 18C6.CA-A1), $\mathrm{CA}$ retains its intramolecular $\mathrm{H}$-bonding and its acceptor $\mathrm{OH}$ is H-bonded to the oxygen of 18C6 (we call it Type-A). Other possible isomers of the18C6. CA complex are shown in Fig. S2b (ESI $\dagger$ ). The calculated IR spectra (black curves) of the three isomers of 18C6.CA are shown below the observed ones. The calculated IR spectrum of 18C6.CA-E1 shows $\mathrm{H}$-bonded $\mathrm{OH}$ stretches at 3372 and $3429 \mathrm{~cm}^{-1}$, and that of 18C6.CA-E4 at 3386 and $3396 \mathrm{~cm}^{-1}$. In the IR spectrum of 18C6.CA-A1, an intermolecular $\mathrm{H}$-bonded $\mathrm{OH}$ appears at $3325 \mathrm{~cm}^{-1}$ and intramolecular $\mathrm{H}$-bonded $\mathrm{OH}$ at $3584 \mathrm{~cm}^{-1}$. Though isomer 18C6.CA-A1, assigned to species $\mathrm{C}_{\mathrm{CA}}$, is the most stable structure, the fluorescence intensity of species $\mathrm{C}_{\mathrm{CA}}$ is rather weak compared to $A_{C A}$ or $B_{C A}$. One of the possibilities of the weakness of this band is a smaller fluorescence quantum yield of this species than that of $\mathrm{A}_{\mathrm{CA}}$ and $\mathrm{B}_{\mathrm{CA}}$. A measurement of the fluorescence lifetime of band $\mathrm{C}_{\mathrm{CA}}$ was unsuccessful because of its weakness, so that it is difficult to discuss the relative abundance of the complexes.

Based on the results of IR measurements, it is concluded that the 18C6.CA complex has two types of isomers having different $\mathrm{H}$-bonding structures. An important point is that 18C6 has an ability to break the intramolecular H-bond of CA, 
which is connected to the drastic changes of the excited state electronic structure of guest CA, as will be discussed later.

\subsection{Energetics of 18C6·benzenediol 1:1 complexes}

As described above, 18C6 and benzenediols form the most stable host-guest complexes at the expense of changing each structure to higher energy ones. In this section, we compare the energies of the bare form in the most stable conformations, and those of the distorted one for forming the complex, and that of the complex. Fig. 7(a) and (b) show the schematic energy diagram of the 18C6.HQ and 18C6.RE systems: the most stable structures of benzenediols and 18C6 (left), distorted structures (middle), and the stable 18C6.benzenediol complexes (right). It should be noted that in the figures the horizontal axis does not mean the complex formation coordinate. In Fig. 7, $\Delta E_{\mathrm{CE}}$ is the energy difference of 18C6 between the most stable structure in the bare form and that in the complex. $\Delta E_{\mathrm{HQ}, \mathrm{RE} \text { or CA }}$ is also the energy difference of the benzenediol part. $E_{\text {int }}$ is the interaction energy of the complex, ${ }^{29}$ which is obtained by using eqn (1) described in the Computational section. In the 18C6.HQ-I complex,
$E_{\text {int }}$ is obtained to be $94.3 \mathrm{~kJ} \mathrm{~mol}^{-1}$. In the case of HQ (Fig. 7(a)), the most stable structure of bare HQ has the trans form. The energy difference between "most stable trans-HQ monomer + most stable 18C6" and 18C6.HQ-I complex corresponds to the binding energy of the 18C6.HQ-I complex. In the complex, the 18C6 and HQ components take higher energy structures, $(18 \mathrm{C6})^{\neq}$ and $(\mathrm{HQ})^{\neq}$(middle in Fig. $7(\mathrm{a})$ ), to form the stable complex (right in Fig. 7(a)). The energy necessary for this distortion, $\left(\Delta E_{\mathrm{CE}}+\Delta E_{\mathrm{HQ}}\right)$, is $10.6 \mathrm{~kJ} \mathrm{~mol}^{-1}$. Hence, the interaction energy $E_{\mathrm{int}}$ is represented by using the binding energy and $\left(\Delta E_{\mathrm{CE}}+\Delta E_{\mathrm{HQ}}\right)$, as follows:

$$
E_{\text {int }}=\text { Binding energy }+\left(\Delta E_{\mathrm{CE}}+\Delta E_{\mathrm{HQ} \text { or RE or CA }}\right)
$$

The BSSE corrected binding energy of the complex is obtained to be $83.7 \mathrm{~kJ} \mathrm{~mol}^{-1}$. This value leads $E_{\text {int }}$ to be $94.3 \mathrm{~kJ} \mathrm{~mol}^{-1}$ by using eqn (2), which is equal to that obtained by using eqn (1). Fig. 7(b) shows the schematic energy diagram for the 18C6.RE complex. The energy difference between the most stable monomers and distorted ones, $\left(\Delta E_{\mathrm{CE}}+\Delta E_{\mathrm{RE}}\right)$, is $31.4 \mathrm{~kJ} \mathrm{~mol}^{-1}$,
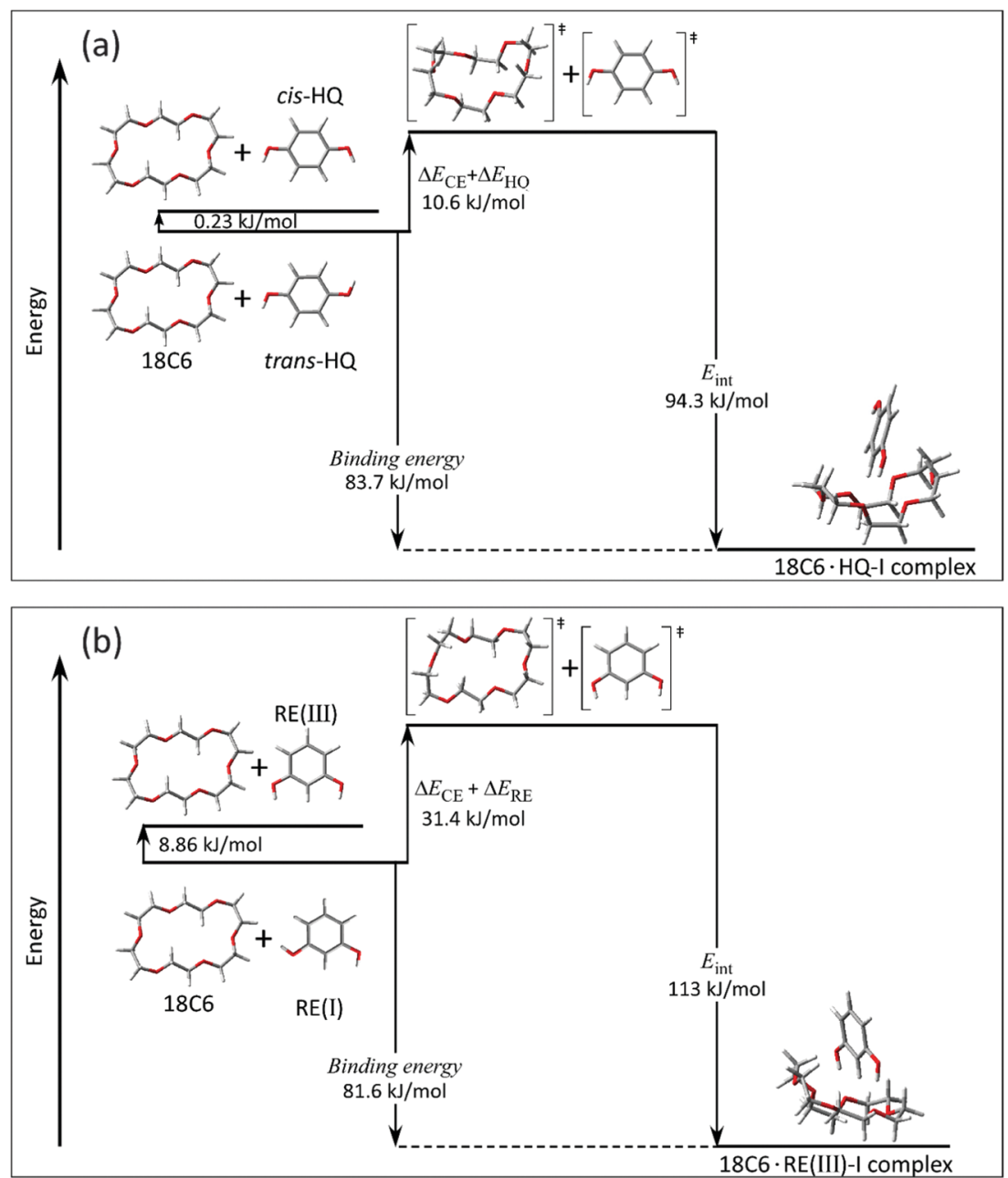

Fig. 7 Energy level of $18 \mathrm{C} 6$ and benzenediol in the most stable conformation in bare forms, that of the distorted ones for forming the complex, and that of the complexes; (a) $18 \mathrm{C} 6 \cdot \mathrm{HQ}$ and (b) $18 \mathrm{C} 6 \cdot \mathrm{RE} . \Delta E_{\mathrm{CE}}, \Delta E_{\mathrm{HQ}}$ and $\Delta E_{\mathrm{RE}}$ represent the destabilization energies due to the distortion of conformation to form the stable complex. $E_{\text {int }}$ represents the interaction energy described in the Computational section (see text). 
the binding energy of the complex is $81.6 \mathrm{~kJ} \mathrm{~mol}^{-1}$, and the interaction energy $E_{\text {int }}$ is $113 \mathrm{~kJ} \mathrm{~mol}^{-1}$.

Fig. 8 shows a similar energy diagram for the 18C6.CA complex system. In this case, two different types of stable complexes are formed, 18C6.CA-A1 and 18C6.E1, as described previously. The value of $\left(\Delta E_{\mathrm{CE}}+\Delta E_{\mathrm{CA}}\right)$ is $12.5 \mathrm{~kJ} \mathrm{~mol}^{-1}$ for 18C6.CA-A1 and $17.3 \mathrm{~kJ} \mathrm{~mol}^{-1}$ for 18C6.CA-E1. The binding energy of the complex is 79.7 for $18 \mathrm{C} 6 \cdot \mathrm{CA}-\mathrm{A} 1$ and $75.8 \mathrm{~kJ} \mathrm{~mol}^{-1}$ for $18 \mathrm{C} 6 \cdot \mathrm{CA}-\mathrm{E} 1$, and $E_{\text {int }}$ is $92.1 \mathrm{~kJ} \mathrm{~mol}^{-1}$ for $18 \mathrm{C} 6 \cdot \mathrm{CA}-\mathrm{A} 1$ and $93.2 \mathrm{~kJ} \mathrm{~mol}^{-1}$ for $18 \mathrm{C} 6 \cdot \mathrm{CA}-\mathrm{E} 1$. Table 2 lists the relative energies of the complexes $(\Delta E), E_{\mathrm{int}}, \Delta E_{\mathrm{CE}}$, $\Delta E_{\mathrm{HQ}}, \Delta E_{\mathrm{RE}}$ and $\Delta E_{\mathrm{CA}}$ and the dihedral angles of $\mathrm{OH}$ groups $\left({ }^{\mathrm{a}} \mathrm{OH},{ }^{\mathrm{b}} \mathrm{OH}\right)$ with respect to the benzene plane. For the benzenediol part, $\Delta E_{\mathrm{HQ}}$ is $1.64-2.11 \mathrm{~kJ} \mathrm{~mol}^{-1}, \Delta E_{\mathrm{RE}}$ is $10.6-12.9 \mathrm{~kJ} \mathrm{~mol}^{-1}$, and $\Delta E_{\mathrm{CA}}$ is $2.28-16.2 \mathrm{~kJ} \mathrm{~mol}^{-1}$. These values are quite different for different species and conformations. As seen in Fig. 7 and 8 and Table 2, all the necessary energies for forming the higher energy conformations are easily compensated by the large interaction energy of 90-110 kJ mol${ }^{-1}$ or the binding energies of $83.7 \mathrm{~kJ} \mathrm{~mol}^{-1}$ for $18 \mathrm{C} 6 \cdot$ cis-HQ-I, $81.6 \mathrm{~kJ} \mathrm{~mol}^{-1}$ for $18 \mathrm{C} 6 \cdot \mathrm{RE}(\mathrm{III})-\mathrm{I}$ and $70.7-$ $79.6 \mathrm{~kJ} \mathrm{~mol}^{-1}$ for 18C6.CA complexes. These binding energies are roughly 4 times larger than the normal $\mathrm{OH} \cdots \mathrm{O} \mathrm{H}$-bond energy (for example the $\mathrm{H}$-bond energy of the water dimer is 19-20 $\left.\mathrm{kJ} \mathrm{mol}^{-1}\right) .{ }^{52}$ Such a large binding energy comes from the multiple interactions between benzenediols and 18C6, such as the $\mathrm{OH} \cdots \mathrm{O} \mathrm{H}$-bond, $\mathrm{CH} \cdots \pi$ and dipole-dipole interactions. These interactions are actually seen in the calculated structures in Fig. 4-6. In these figures, the number of $\mathrm{OH} \cdots \mathrm{O}$ and $\mathrm{CH} \cdots \pi$ bonding are also shown; the most stable isomers have the largest number of intermolecular bonding between the host and guest molecules. These results strongly indicate that the 18C6. benzenediol host-guest complex formation is not described as a simple rigid "lock-and-key" model, but as a flexible "inducedfit" model, like an enzyme-substrate fitting.

\subsection{The $S_{1}$ lifetime of $18 C 6 \cdot$ benzenediol complexes}

The observed $\mathrm{S}_{1}$ lifetimes of benzenediols and 18C6 benzenediol complexes are also listed in Table 1. As described in the Introduction section, the major non-radiative pathway of the $\mathrm{S}_{1}$ state of benzenediols is thought to be IC to $\mathrm{S}_{2}\left(\pi \sigma^{*}\right)$ via the conical intersection, followed by the $\mathrm{O}-\mathrm{H}$ bond fission along the repulsive $S_{2}$ potential curve or the further IC to $S_{0}$ via the $\mathrm{S}_{2}-\mathrm{S}_{0}$ conical intersection. Anomalous short lifetime of bare CA ( $8 \mathrm{ps})$ is described by the low barrier height of the $\mathrm{S}_{1}-\mathrm{S}_{2}$ conical intersection due to the small $\mathrm{S}_{1} / \mathrm{S}_{2}$ energy gap $\left(\Delta E_{2-1}\right)$ and low symmetry $\left(C_{1}\right)$ in the $S_{1}$ state. ${ }^{53,54}$ So, we calculated the vertical excitation energies to the $S_{1}$ and $S_{2}$ states with the fixed $\mathrm{S}_{0}$ geometry and obtained the $\mathrm{S}_{1}-\mathrm{S}_{2}$ energy gap $\Delta E_{2-1}$, which is also listed in Table 1 . Since we do not calculate the potential energy curves along the $\mathrm{O} \cdots \mathrm{H}$ coordinate, $\Delta E_{2-1}$ is not equal to the barrier height at the $S_{1}-S_{2}\left(\pi \sigma^{*}\right)$ conical intersection. Even if it is so, we consider that this value is roughly proportional to the barrier height. The calculated $\Delta E_{2-1}$ of bare HQ and RE is 0.439-0.571 eV, while that of CA is much smaller, $0.256 \mathrm{eV}$. This difference is in good agreement with the shorter $S_{1}$ lifetime of CA than HQ or RE. The complex formation with 18C6 greatly affects the nonradiative process of each benzenediol in a different manner. First, in the case of $H Q$, the $S_{1}$ lifetime is shortened by a factor of five $(2.6 \mathrm{~ns} \rightarrow 0.54 \mathrm{~ns})$ in the complex, while the lifetime is 2.5 times lengthened in the RE complex ( $4.0 \mathrm{~ns} \rightarrow 10.5 \mathrm{~ns}$ ) and 1280 times in the Type-E complex of CA (8.0 ps $\rightarrow 10.3 \mathrm{~ns}$ ). Thus, the 18C6.HQ complex shows an opposite trend of the $S_{1}$ lifetime behavior compared to that of

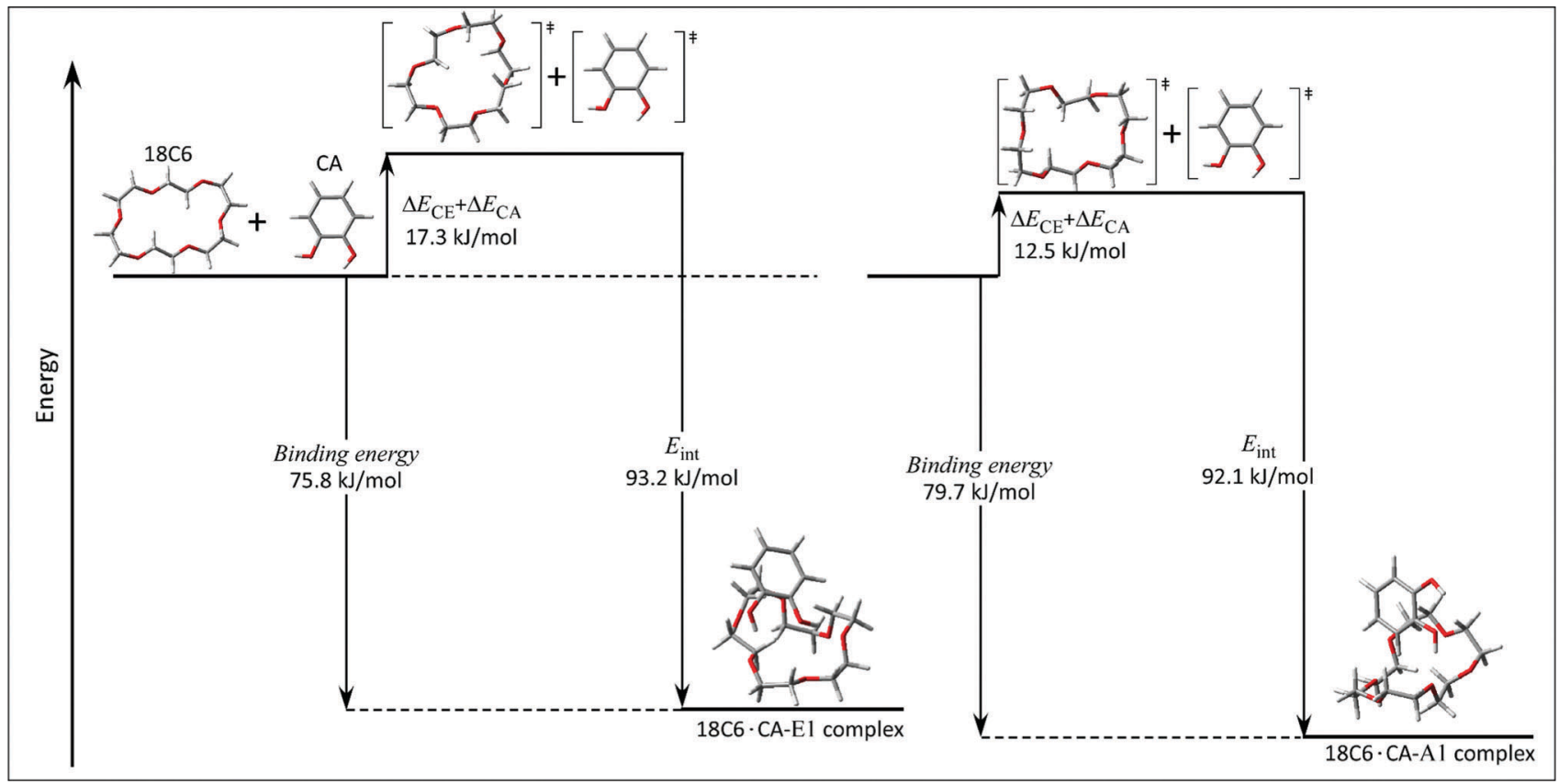

Fig. 8 Energy level of $18 C 6$ and $C A$ in the most stable conformation in bare forms and that of the distorted ones for forming the complex. $\Delta E_{C E}$ and $\Delta E_{\mathrm{CA}}$ represent the destabilization energy due to the distortion to form the stable host-guest complex. $E_{\text {int }}$ represents the interaction energy described in the Computational section (see text). 
18C6.RE and 18C6.CA. This difference is attributed to the presence of free $\mathrm{OH}$ in 18C6.HQ but not in 18C6.RE and 18C6.CA. As seen in Table 1, the presence of free $\mathrm{OH}$ does not affect strongly the $\Delta E_{2-1}$ value: $0.471 \mathrm{eV}$ for $\mathrm{RE}(\mathrm{I})$ changes to $0.512 \mathrm{eV}$ for $18 \mathrm{C} 6 \cdot \mathrm{RE}$ (III)-I and $0.488 \mathrm{eV}$ for cis-HQ changes to $0.496 \mathrm{eV}$ for 18C6.HQ-II. Only CA shows a large change in the $\Delta E_{2-1}$ value upon complex formation: $0.256 \mathrm{eV}$ for $\mathrm{CA} \rightarrow 0.721 \mathrm{eV}$ for 18C6.CA-E1. However, the difference can be seen clearly in the molecular orbitals of the electronic states between 18C6.HQ, 18C6.RE and 18C6.CA. The molecular orbitals responsible for the $S_{1}$ and $S_{2}$ electronic sates are shown in Fig. S3 (ESI $\dagger)$. In the figure, it is clear that the $\sigma^{*}$ character dominates in the $S_{2}$ state in all the monomer species. On the other hand, for the $18 \mathrm{C} 6$ complexes, the $\sigma^{*}$ character can be seen only at the free $\mathrm{OH}$ site of 18C6.HQ (Fig. S3(c), ESI $\dagger$ ). In addition, the dihedral angle defined in Scheme 1 of cis-HQ becomes 168-178 degree, indicating that the molecular symmetry of cis-HQ becomes lower from $C_{2 \mathrm{~h}}$ to $C_{1}$ by complexation. Hence, this lower molecular symmetry causes the shorter $S_{1}$ lifetime of HQ upon complexation. In the case of 18C6.RE and 18C6.CA, the cage of $18 \mathrm{C} 6$ diminishes the $\sigma^{*}$ character in the $S_{2}$ state, leading to the suppression of the $\mathrm{OH}$ cleavage. Rizzo and co-workers observed a similar lifetime elongation in a protonated tryptophan$\left(\mathrm{H}_{2} \mathrm{O}\right)_{2}$ complex. $^{55}$ The protonation to tryptophan lowers the energy of the $\pi \sigma^{*}\left(\sigma^{*}\right.$ of $\left.\mathrm{N}-\mathrm{H}\right)$ state, facilitating a mixing between the $\pi \sigma^{*}$ and indole $\pi \pi^{*}$ states. Thus, the protonated tryptophan monomer exhibits a very broad electronic spectrum. In contrast, the hydration to the $\mathrm{NH}_{3}^{+}$group by two water molecules shifts the $\sigma^{*}$ of $\mathrm{N}-\mathrm{H}$ to higher energy, resulting in the decoupling of $\pi \sigma^{*}$ from $\pi \pi^{*}$. In other words, two water molecules "block" the $\mathrm{N}-\mathrm{H}$ bond fission of protonated tryptophan in the excited state, resulting in the sharp electronic spectrum. In the case of $18 \mathrm{C} 6 \cdot \mathrm{HQ}$, the $\pi \sigma^{*}$ character is still retained in the free $\mathrm{OH}$ group in the $\mathrm{S}_{2}$ sate as seen in Fig. S3(e) (ESI $\dagger)$.

\section{Conclusion}

In the present study, we investigated the formation of host-guest complexes between 18C6 and benzenediols in the gas phase under supersonically jet-cooled conditions. We found that 18C6 and benzenediols cooperatively change their conformations from the stable bare forms to higher energy ones for the best-fitted stable complexes. The complexes are stabilized synergistically through multiple interactions. Especially, the RE part in 18C6.RE takes the characteristic conformation (RE(III)), which is the highest energy one in the monomer form. In the 18C6.CA Type-E complex, CA breaks its intramolecular $\mathrm{H}$-bond to form two intermolecular H-bonds with 18C6. It is also found that complex formation controls the direction of the $\mathrm{OH}$ group remote from the direct contact. All the complexes are stabilized by synergetic intermolecular interactions, which are produced by the geometry changes of the host and guest species via a typical "induced-fit" mechanism.

It was also found that the host-guest complexation with crown ethers drastically changes the electronic excited state of guest species. In the case of $\mathrm{RE}$ and $\mathrm{CA}$, the $\mathrm{S}_{1}$ lifetime is lengthened by a factor of 2.5 and 1280, respectively. This drastic change is described partly by an increase of the $S_{1} / S_{2}$ energy gap and mostly by the destruction of the $\pi \sigma^{*}$ character of the $S_{2}$ state. In contrast, in $\mathrm{HQ}$, the complexation shortens the $\mathrm{S}_{1}$ lifetime of HQ by a factor of five, thus accelerating the nonradiative decay rate. The present study has shown that 18C6, a simple crown ether, can exert isomeric preference and modify the excited state dynamics of guest species through multiple interactions. In future work, we will extend this work to more flexible molecules as guest molecules and elucidate the potential ability of crown ether to control the conformer preference as well as the excited state dynamics of the guest.

\section{Acknowledgements}

T. E. acknowledges the Japan Society for the Promotion of Science (JSPS) for the support through a Grant-in-Aid project (No. 25410017).

\section{References}

1 C. J. Pedersen, J. Am. Chem. Soc., 1967, 89, 7017-7036.

2 C. J. Pedersen and H. K. Frensdorff, Angew. Chem., Int. Ed. Engl., 1972, 11, 16-25.

3 C. J. Pedersen, Science, 1988, 241, 536-540.

4 R. M. Izatt, J. H. Rytting, D. P. Nelson, B. L. Hayamore and J. J. Christensen, Science, 1969, 164, 443-444.

5 R. M. Izatt, D. P. Nelson, J. H. Rytting and J. J. Christensen, J. Am. Chem. Soc., 1971, 93, 1619-1623.

6 R. M. Izatt, R. E. Terry, B. L. Haymore, L. D. Hansen, N. K. Dalley, A. G. Avondet and J. J. Christensen, J. Am. Chem. Soc., 1976, 98, 7620-7626.

7 R. M. Izatt, R. E. Terry, D. P. Nelson, Y. Chan, D. J. Eatough, J. S. Bradshaw, L. D. Hansen and J. J. Christensen, J. Am. Chem. Soc., 1976, 98, 7626-7630.

8 J. D. Lamb, R. M. Izatt, C. S. Swain and J. J. Christensen, J. Am. Chem. Soc., 1980, 102, 475-479.

9 H. Zhang, J. H. Chu, S. Leming and D. V. Dearden, J. Am. Chem. Soc., 1991, 113, 7415-7417.

10 H. Zhang and D. V. Dearden, J. Am. Chem. Soc., 1992, 114, 2754-2755.

11 S. Maleknia and J. Brodbelt, J. Am. Chem. Soc., 1992, 114, 4295-4298.

12 I. H. Chu, H. Zhang and D. V. Dearden, J. Am. Chem. Soc., 1993, 115, 5736-5744.

13 L. X. Dang, J. Am. Chem. Soc., 1995, 117, 6954-6960.

14 P. D. J. Grootenhuis and P. A. Kollman, J. Am. Chem. Soc., 1989, 111, 2152-2158.

15 D. Ray, D. Feller, M. B. More, E. D. Glendening and P. B. Armentrout, J. Phys. Chem., 1996, 100, 16116-16125.

16 F. Sobott, W. Kleinekofort and B. Brutschy, Anal. Chem., 1997, 69, 3587-3594.

17 M. B. More, D. Ray and P. B. Armentrout, J. Phys. Chem. A, 1997, 101, 4254-4262. 
18 M. B. More, D. Ray and P. B. Armentrout, J. Phys. Chem. A, 1997, 101, 7007-7017.

19 M. B. More, D. Ray and P. B. Armentrout, J. Am. Chem. Soc., 1999, 121, 417-423.

20 Y. Inokuchi, O. V. Boyarkin, R. Kusaka, T. Haino, T. Ebata and T. R. Rizzo, J. Am. Chem. Soc., 2011, 133, 12256-12263.

21 Y. Inokuchi, O. V. Boyarkin, R. Kusaka, T. Haino, T. Ebata and T. R. Rizzo, J. Phys. Chem. A, 2012, 116, 4057-4068.

22 Y. Inokuchi, R. Kusaka, T. Ebata, O. V. Boyarkin and T. R. Rizzo, ChemPhysChem, 2013, 14, 649-660.

23 Y. Inokuchi, T. Mizuuchi, T. Ebata, T. Ikeda, T. Haino, T. Kimura, H. Guo and Y. Furutani, J. Am. Chem. Soc., 2014, 592, 90-95.

24 Y. Inokuchi, T. Ebata, T. R. Rizzo and O. V. Boyarkin, Chem. Phys. Lett., 2014, 136, 1815-1824.

25 R. Kusaka, Y. Inokuchi and T. Ebata, Phys. Chem. Chem. Phys., 2007, 9, 4452-4459.

26 R. Kusaka, Y. Inokuchi and T. Ebata, Phys. Chem. Chem. Phys., 2008, 10, 6238-6244.

27 R. Kusaka, Y. Inokuchi and T. Ebata, Phys. Chem. Chem. Phys., 2009, 11, 9132-9140.

28 S. Kokubu, R. Kusaka, Y. Inokuchi, T. Haino and T. Ebata, Phys. Chem. Chem. Phys., 2010, 12, 3559-3565.

29 R. Kusaka, Y. Inokuchi, T. Haino and T. Ebata, J. Phys. Chem. Lett., 2012, 3, 1414-1420.

30 Y. Inokuchi, O. V. Boyarkin, T. Ebata and T. R. Rizzo, Phys. Chem. Chem. Phys., 2012, 14, 4457-4462.

31 F. Morishima, R. Kusaka, Y. Inokuchi, T. Haino and T. Ebata, J. Phys. Chem. B, 2015, 119, 2557-2565.

32 Y. Inokuchi, Y. Kobayashi, T. Ito and T. Ebata, J. Phys. Chem. A, 2007, 111, 3209-3215.

33 R. J. Lipert and S. D. Colson, J. Phys. Chem., 1989, 93, 3894-3896.

34 Y. Yamada, N. Mikami and T. Ebata, Proc. Natl. Acad. Sci. U. S. A., 2008, 105, 12690-12695.

35 R. Kusaka and T. Ebata, Angew. Chem., Int. Ed., 2010, 49, 6989-6992.

36 I. Kolossváry and W. C. Guida, J. Am. Chem. Soc., 1996, 118, 5011-5019.

37 MacroModel, version 9.1, Schrödinger, LLC, New York, 2005. 38 T. A. Halgren, J. Comput. Chem., 1999, 20, 730-748.

39 M. J. Frisch, G. W. Trucks, H. B. Schlegel, G. E. Scuseria, M. A. Robb, J. R. Cheeseman, G. Scalmani, V. Barone, B. Mennucci, G. A. Petersson, H. Nakatsuji, M. Caricato, X. Li, H. P. Hratchian, A. F. Izmaylov, J. Bloino, G. Zheng, J. L. Sonnenberg, M. Hada, M. Ehara, K. Toyota, R. Fukuda, J. Hasegawa, M. Ishida, T. Nakajima, Y. Honda, O. Kitao, H. Nakai, T. Vreven, J. A. Montgomery, Jr., J. E. Peralta, F. Ogliaro, M. Bearpark, J. J. Heyd, E. Brothers, K. N. Kudin,
V. N. Staroverov, R. Kobayashi, J. Normand, K. Raghavachari, A. Rendell, J. C. Burant, S. S. Iyengar, J. Tomasi, M. Cossi, N. Rega, J. M. Millam, M. Klene, J. E. Knox, J. B. Cross, V. Bakken, C. Adamo, J. Jaramillo, R. Gomperts, R. E. Stratmann, O. Yazyev, A. J. Austin, R. Cammi, C. Pomelli, J. W. Ochterski, R. L. Martin, K. Morokuma, V. G. Zakrzewski, G. A. Voth, P. Salvador, J. J. Dannenberg, S. Dapprich, A. D. Daniels, Ö. Farkas, J. B. Foresman, J. V. Ortiz, J. Cioslowski and D. J. Fox, Gaussian 09, Revision D.01, Gaussian, Inc., Wallingford CT, 2009.

40 S. J. Humphrey and D. W. Pratt, J. Chem. Phys., 1993, 99, 5078 (J. Chem. Phys., 1996, 104, 2752).

41 P. S. Meenakshi, N. Biswasa and S. Wategaonkar, Phys. Chem. Chem. Phys., 2003, 5, 294-299.

42 M. Gerhards, W. Perl and K. Kleinermanns, Chem. Phys. Lett., 1995, 240, 506-512.

43 S. Melandri, G. Maccaferri, W. Caminati and P. G. Favero, Chem. Phys. Lett., 1996, 256, 513-517.

44 M. Gerhards, C. Unterberg and K. Kleinermanns, Phys. Chem. Chem. Phys., 2000, 2, 5538-5544.

45 K. Hattori and S. Ishiuchi, J. Phys. Chem. A, 2007, 111, 6028-6033.

46 R. A. Livingstone, J. O. F. Thompson, M. Iljina, R. J. Donaldson, B. J. Sussman, M. J. Paterson and D. Townsend, J. Chem. Phys., 2012, 137, 184304.

47 A. S. Chatterley, J. D. Young, D. Townsend, J. M. Żurek, M. J. Paterson, G. M. Roberts and V. G. Stavros, Phys. Chem. Chem. Phys., 2013, 15, 6879-6892.

48 G. Wipff, P. Weiner and P. Kollman, J. Am. Chem. Soc., 1982, 104, 3249-3258.

49 Y. Sun and P. A. Kollman, J. Chem. Phys., 1992, 97, 5108.

50 E. D. Glendening, D. Feller and M. A. Thompson, J. Am. Chem. Soc., 1994, 116, 10657-10669.

51 M. J. Bovill, D. J. Chadwick, I. O. Sutherland and D. Watkin, J. Chem. Soc., Perkin Trans. 2, 1980, 1529-1543.

52 M. W. Feyereisen, D. Feller and D. A. Dixon, J. Phys. Chem., 1996, 100, 2993-2997.

53 (a) M. Gerhards, C. Unterberg and S. Schumm, J. Chem. Phys., 1999, 111, 7966; (b) W. B. Tzeng, K. Narayanan, C. Y. Hsieh and C. C. Tung, Spectrochim. Acta, Part A, 1997, 53, 2595-2604; (c) S. J. Humphrey and D. W. Pratt, J. Chem. Phys., 1993, 99, 5078; (d) G. A. King, T. A. A. Oliver, R. N. Dixon and M. N. R. Ashfold, Phys. Chem. Chem. Phys., 2012, 14, 3338-3345.

54 M. Weiler, M. Miyazaki, G. Féraud, S. Ishiuchi, C. Dedonder, C. Jouvet and M. Fujii, J. Phys. Chem. Lett., 2013, 4, 3819-3823. 55 S. R. Mercier, O. V. Boyarkin, A. Kamariotis, M. Guglielmi, I. Tavernelli, M. Cascella, U. Rothlisberger and T. R. Rizzo, J. Am. Chem. Soc., 2006, 128, 16938-16943. 